\title{
Plasma and dietary carotenoid, retinol and tocopherol levels and the risk of gastric adenocarcinomas in the European prospective investigation into cancer and nutrition
}

\author{
M Jenab*,', E Riboli', P Ferrari', M Friesen', J Sabate ${ }^{1,2}$, T Norat', N Slimani', A Tjønneland ${ }^{3}$, A Olsen ${ }^{3}$, \\ K Overvad $^{4}$, M-C Boutron-Ruault ${ }^{5}$, F Clavel-Chapelon ${ }^{5}$, H Boeing ${ }^{6}$, M Schulz ${ }^{6}$, J Linseisen ${ }^{7}$, G Nagel $^{7}$, \\ A Trichopoulou ${ }^{8}$, A Naska ${ }^{8}$, E Oikonomou ${ }^{8}$, F Berrino', S Panico ${ }^{10}$, D Palli' ', C Sacerdote ${ }^{12}$, R Tumino ${ }^{13}$, \\ $\mathrm{PH}$ Peeters $^{14}$, ME Numans ${ }^{14}$, HB Bueno-de-Mesquita ${ }^{15}$, FL Büchner ${ }^{15}$, E Lund ${ }^{16}$, G Pera ${ }^{17}$, MD Chirlaque ${ }^{18}$, \\ M-J Sánchez $z^{19}$, L Arriola ${ }^{20}$, A Barricarte ${ }^{21}$, JR Quirós ${ }^{22}$, I Johansson ${ }^{23}$, A Johansson ${ }^{23}$, G Berglund ${ }^{24}$, \\ S Bingham ${ }^{25}$, K-T Khaw ${ }^{26}$, N Allen ${ }^{27}$, T Key ${ }^{27}$, F Carneiro ${ }^{28}$, V Save ${ }^{29}$, G Del Giudice ${ }^{30}$, M Plebani ${ }^{31}$, \\ R Kaaks' and CA Gonzalez ${ }^{17}$
}

'Nutrition and Hormones Group, IARC-WHO, Lyon, France; ${ }^{2}$ Department of Nutrition, Loma Linda University, Loma Linda, CA, USA; ${ }^{3}$ Institute of Cancer Epidemiology, Danish Cancer Society, Copenhagen, Denmark; ${ }^{4}$ Department of Clinical Epidemiology, Aalborg Hospital, Aarhus University Hospital, Aalborg, Denmark; ${ }^{5}$ INSERM Department ERI 20, Institut Gustave Roussy, Villejuif, France; ${ }^{6}$ Department of Epidemiology, German Institute of Human Nutrition, Potsdam-Rehbücke, Germany; ${ }^{7}$ Department of Clinical Epidemiology, Deutsches Krebsforschungszentrum, Heidelberg, Germany; ${ }^{8}$ Department of Hygiene and Epidemiology, Medical School, University of Athens, Athens, Greece; ${ }^{9}$ Epidemiology Unit, Istituto Tumori, Milan, Italy; ${ }^{10}$ Department of Clinical and Experimental Medicine, Federico II University, Naples, Italy; "'Molecular and Nutritional Epidemiology Unit, CSPO-Scientific Institute of Tuscany, Florence, Italy; ${ }^{2}$ University of Turin and CPO-Piemonte, Turin, Italy; ${ }^{13}$ Cancer Registry, Azienda Ospedaliera 'Civile MP Arezzo', Ragusa, Italy; ${ }^{14}$ Julius Centre for Health Sciences and Primary Care, University Medical Center, Utrecht, The Netherlands; ${ }^{15}$ Centre for Nutrition and Health, National Institute for Public Health and the Environment, Bilthoven, The Netherlands; ${ }^{16}$ Institute of Community Medicine, University of Tromso, Tromso, Nonway; ${ }^{17}$ Department of Epidemiology, Catalan Institute of Oncology, Barcelona (ICO-IDIBELL), Spain; ${ }^{18}$ Servicio de Epidemiología, Consejería de Sanidad y Consumo, Murcia, Spain; ${ }^{19}$ Andalusian School of Public Health, Granada, Spain; ${ }^{20}$ Public Health Department of Guipuzkoa, San Sebastian, Spain; ${ }^{21}$ Public Health Institute of Navarra, Pamplona, Spain; ${ }^{22}$ Sección Información Sanitaria, Consejería de Salud y Servicios Sanitarios de Asturias, Asturias, Spain; ${ }^{23}$ Department of Odontology, Faculty of Medicine, Umeå University, Umeå, Sweden; ${ }^{24}$ Department of Medical Epidemiology, Karolinska Instututet, Stockholm, Sweden; ${ }^{25}$ Department of Public Health and Primary Care, Centre for Nutrition and Cancer Prevention and Survival, University of Cambridge, Cambridge, UK; ${ }^{26}$ Clinical Gerontology Unit, University of Cambridge, Cambridge, UK; ${ }^{27}$ Cancer Epidemiology Unit, University of Oxford, Oxford, UK; ${ }^{28}$ Institute of Molecular Pathology and Immunology of the University of Porto (IPATIMUP) and Medical Faculty of Porto/HS Joao, Porto, Portugal; ${ }^{29}$ Department of Histopathology, Addenbrooke's Hospital, Cambridge, UK; ${ }^{30}$ Novartis Vaccines, Research Center, Siena, Italy; ${ }^{3 /}$ Servizio di Medicina di Laboratorio, Azienda Ospedaliera di Padova, Padova, Italy

Despite declining incidence rates, gastric cancer (GC) is a major cause of death worldwide. Its aetiology may involve dietary antioxidant micronutrients such as carotenoids and tocopherols. The objective of this study was to determine the association of plasma levels of seven common carotenoids, their total plasma concentration, retinol and $\alpha$ - and $\gamma$-tocopherol, with the risk of gastric adenocarcinoma in a case-control study nested within the European Prospective Investigation into Cancer and Nutrition (EPIC), a large cohort involving 10 countries. A secondary objective was to determine the association of total sum of carotenoids, retinol and $\alpha$-tocopherol on GCs by anatomical subsite (cardia/noncardia) and histological subtype (diffuse/intestinal). Analytes were measured by high-performance liquid chromatography in prediagnostic plasma from 244 GC cases and 645 controls matched by age, gender, study centre and date of blood donation. Conditional logistic regression models adjusted by body mass index, total energy intake, smoking and Helicobacter pylori infection status were used to estimate relative cancer risks. After an average 3.2 years of follow-up, a negative association with GC risk was observed in the highest vs the lowest quartiles of plasma $\beta$-cryptoxanthin (odds ratio $(\mathrm{OR})=0.53,95 \%$ confidence intervals $\left.(C l)=0.30-0.94, P_{\text {trend }}=0.006\right)$, zeaxanthin $\left(O R=0.39,95 \% \mathrm{Cl}=0.22-0.69, P_{\text {trend }}=0.005\right)$, retinol $(O R=0.55,95 \% \mathrm{Cl}=0.33-0.93$, $\left.P_{\text {trend }}=0.005\right)$ and lipid-unadjusted $\alpha$-tocopherol $\left(O R=0.59,95 \% \mathrm{Cl}=0.37-0.94, P_{\text {trend }}=0.022\right)$. For all analytes, no heterogeneity of risk estimates or significant associations were observed by anatomical subsite. In the diffuse histological subtype, an inverse association was observed with the highest vs lowest quartile of lipid-unadjusted $\alpha$-tocopherol $\left(O R=0.26,95 \% \mathrm{Cl}=0.1 \mathrm{I}-0.65, P_{\text {trend }}=0.003\right)$. These results show that higher plasma concentrations of some carotenoids, retinol and $\alpha$-tocopherol are associated with reduced risk of GC. British Journal of Cancer (2006) 95, 406-4I5. doi: I0.1038/sj.bjc.6603266 www.bjcancer.com

Published online II July 2006

(c) 2006 Cancer Research UK

Keywords: carotenoids; tocopherol; retinol; gastric cancer; diet; EPIC

*Correspondence: Dr M Jenab; E-mail: Jenab@iarc.fr

Received 20 March 2006; revised 9 June 2006; accepted I4 June 2006;

published online II July 2006 
Gastric cancer (GC) presents wide international variation in incidence rates, with a general overall decline in the past several decades (Kelley and Duggan, 2003). In Western countries, the overall decline in GC incidence has been contrasted by a relative increase in cardial GC rates (Botterweck et al, 2000a; Corley and Kubo, 2004) and, from a histological point of view, the diffuse subtype is becoming relatively more common (Lauren and Nevalainen, 1993). GC risk factors may differ based on the histological subtype, or the anatomical localisation of GCs within the stomach (Correa and Shiao, 1994; Engel et al, 2003; Kelley and Duggan, 2003).

The intake of some fruits and vegetables has been suggested to be inversely associated with the risk of GCs (World Cancer Research Fund, 1997; Riboli and Norat, 2003; Gonzalez et al, 2006), an effect that may be owing to the various carotenoids and antioxidant vitamins present in these foods (Donaldson, 2004). Several case-control studies have shown strong inverse associations between GC risk and higher consumption of some of these nutrients (Buiatti et al, 1990, 1991; Gonzalez et al, 1994; Hansson et al, 1994; Ekstrom et al, 2000). Results from prospective dietary studies are conflicting and show either a strong protection (Zheng et al, 1995) or no clear inverse associations between the dietary intake of carotenoids and GC risk (Ocke et al, 1995; Botterweck et al, 2000b).

However, estimation of dietary carotenoid intakes is prone to many measurement errors and may not reflect their actual bioavailability, which can be better estimated by measures of circulating blood carotenoid levels. Certain plasma carotenoids can be considered as biomarkers of intake of fruits and vegetables (Al Delaimy et al, 2005a,b). Some earlier studies in Western populations (Willett et al, 1984; Stahelin et al, 1991) and more recent ones in high-risk Chinese populations (Abnet et al, 2003; Taylor et al, 2003; Yuan et al, 2004) show a higher GC risk in those with lower blood levels of some carotenoids or retinol. In contrast, some recent studies show a positive association between blood $\alpha$-tocopherol levels and risk of GCs of the stomach cardia (Nouraie et al, 2005) and noncardial regions (Taylor et al, 2003) as well as the progression of dysplastic lesions to GCs (You et al, 2000). Only a few of the studies to date have been prospective in nature, few have considered histological subtype or anatomical tumour location and fewer still have accounted for Hp infection, a strong potential confounding factor. Further, it is unclear whether any observed association is conferred by individual carotenoids or is owing to the combined effect of blood carotenoids. Thus, the aim of this study was to determine the association of plasma levels of seven common individual carotenoids, retinol and $\alpha$ - and $\gamma$-tocopherols as well as total blood carotenoid levels with risk of $\mathrm{GC}$, with consideration of $\mathrm{Hp}$ infection status, in a case-control study nested within the European Prospective Investigation into Cancer and Nutrition (EPIC-EURGAST). The effects of the total sum of carotenoids as well as the effects of retinol and $\alpha$-tocopherol were further explored by anatomical subsite and histological subtype. In addition, the association of dietary $\beta$-carotene, retinol and vitamin $\mathrm{E}$ with GC risk was also assessed.

\section{MATERIALS AND METHODS}

\section{Study population and collection of blood samples}

The rationale and methods of the EPIC study have been previously discussed in detail (Riboli and Kaaks, 1997; Riboli et al, 2002). Briefly, the EPIC cohort consists of 23 centres in 10 European countries (Denmark, France, Greece, Germany, Italy, Netherlands, Norway, Spain, Sweden and United Kingdom). Between 1992 and 1998, country-specific dietary questionnaires, standardised lifestyle and personal history questionnaires, anthropometric data and blood samples were collected. Values for total energy intake and dietary $\beta$-carotene (the only dietary carotenoid currently available in the EPIC dietary database), retinol and vitamin E (includes $\alpha$ - and $\gamma$-tocopherols along with other tocopherols and tocotrienols) were computed using country-specific food composition tables.

In each of the 23 recruitment centres, blood samples of at least $30 \mathrm{ml}$ were drawn from all participants and stored at $5-10^{\circ} \mathrm{C}$ protected from light and transported to local laboratories for processing and aliquoting (Riboli and Kaaks, 1997; Riboli et al, 2002). The only exceptions were the EPIC-Oxford centre (UK), where blood samples were collected from a network of general practitioners and transported to a central laboratory by post and centres in Sweden and Denmark where blood was aliquoted within $1 \mathrm{~h}$ of drawing. Previous studies have shown that carotenoids are not appreciably affected by short-term storage and transport (Hankinson et al, 1989; Key et al, 1996).

In all countries, except Denmark and Sweden, blood was separated into $0.5 \mathrm{ml}$ fractions (serum, plasma, red cells and buffy coat for DNA extraction). Each fraction was placed into straws, which were heat-sealed and stored $\left(-196^{\circ} \mathrm{C}\right)$ under liquid nitrogen. In Denmark, blood fraction aliquots of $1.0 \mathrm{ml}$ were stored locally in Nunc tubes at $-150^{\circ} \mathrm{C}$ under nitrogen vapour. In Sweden, samples were stored in $-80^{\circ} \mathrm{C}$ freezers.

\section{Follow-up for cancer incidence and vital status}

In EPIC, follow-up is based on population cancer registries (Denmark, Italy, Netherlands, Norway, Spain, Sweden and the United Kingdom) and other methods, such as health insurance records, pathology registries and active contact of study subjects or next of kin (France, Germany and Greece). The follow-up period for the present study was for data reports received to the end of October 2002, representing complete follow-ups until either December 2000 or December 2001 for all centres using cancer registry data and until 2002 for France, Germany and Greece. Cancers of the stomach included cancers coded as C16 (10th Revision of the International Statistical Classification of Diseases, Injury and Causes of Death). The diagnosis, tumour site classification and morphology (according to ICDO2 and Lauren classifications) of each identified cancer was confirmed and validated by an independent panel of pathologists with a representative from each EPIC country and a coordinator using original histological slides and/or re-cuts from the paraffin blocks and histopathology reports.

\section{Nested case-control study design and selection of study subjects}

Incident cases were study subjects who developed GC after recruitment into EPIC. The present study includes a total of 228 gastric adenocarcinomas and 16 adenocarcinomas of the gastro-oesophageal junction (GEJ), which are grouped together ( $n$ matched controls $=645$ ) and referred to as GC. GC were divided into the following three groups by anatomical subsite: (i) tumours originating from the gastric cardia ( $n$ cases $=70, n$ matched controls $=176$ ), combining tumours that reached the GEJ, either crossing it or from below (all 16 GEJ cancers) or not, (ii) noncardial tumours ( $n$ cases $=127, n$ matched controls $=344$ ) grouping cases from other sites in the stomach and (iii) tumours from unknown or mixed sites ( $n$ cases $=47, n$ matched controls $=125)$. When divided by histological subtype, of the 244 GC cases, 93 ( $n$ matched controls $=244$ ) were classified as diffuse, and 96 ( $n$ matched controls $=256)$ as intestinal according to the Lauren classification. The remainder ( $n$ cases $=55, n$ matched controls $=145$ ) were of unknown or mixed histological types. All gastric lymphomas, gastric stump cancers, other gastric nonadenocarcinoma and otherwise unspecified cancers of the stomach were excluded from this analysis. For each identified cancer case, control subjects with available blood samples were randomly 
selected from all cohort members who were alive and free of cancer (except nonmelanoma skin cancer) at the time of diagnosis of the case patient. Controls were matched by gender, age group $( \pm 2.5$ years), study centre and date of blood sample collection $( \pm 45$ days). The study was conducted in two phases. The target case to control matching ratio was $1: 4$ for the first phase (88 GC cases) and $1: 2$ for the second phase (156 GC cases). This study was approved by the Ethical Review Board of the International Agency for Research on Cancer (IARC, Lyon, France) and those of all individual EPIC centres.

\section{Laboratory assay - Helicobacter pylori infection status}

The methodology for the determination of $\mathrm{Hp}$ infection status is detailed elsewhere (Gonzalez et al, 2006; Palli et al, 2006). Briefly, quantification of anti-Hp antibodies in plasma of all cases and controls was performed by ELISA using the lysate of the Hp CCUG strain. Various dilutions of plasma samples (starting dilution $1: 200$ ) were incubated with the Hp lysate in solid phase $\left(1 \mu \mathrm{g} \mathrm{ml}^{-1}\right)$. After $1 \mathrm{~h}$ and extensive washings, plates were incubated with an alkaline phosphatase-conjugated polyclonal affinity-purified goat anti-human IgG (Sigma chemical Co., St Louis, MO, USA). After $3 \mathrm{~h}$ incubation and further washings, the enzymatic reaction was revealed by the addition of $p$-nitrophenylphosphate as a substrate. Hp-specific IgG antibody titres were expressed as ELISA Units (EU), and were determined by interpolation relative to a standard curve constructed by a serial dilution of a standard positive control. A cutoff value of $100 \mathrm{EU}$ was defined using serum samples from individuals negative for $H$. pylori infection as determined by clinical, microbiological and serological assays. Serum samples with EU values above 100 were considered as positive for anti- $H$. pylori IgG antibodies. In previous experiments, this assay exhibited specificity and sensitivity higher than $90 \%$.

\section{Laboratory assay - analytes}

All analyses were performed at IARC. Plasma samples were analysed for seven carotenoids ( $\alpha$-carotene, $\beta$-carotene, $\beta$-cryptoxanthin, canthaxanthin, lutein, lycopene and zeaxanthin), as well as retinol, $\alpha$-tocopherol and $\gamma$-tocopherol using a reverse-phase high-performance liquid chromatography method (HPLC) (Steghens et al, 1997) on an HPLC-1100 system (Hewlett Packard, Wilmington, IL, USA) with a C18-Adsorbosphere column (Alltech, Deerfield, IL, USA). Plasma samples $(200 \mu \mathrm{l})$ were thawed and deproteinated with alcohol, extracted with hexane, dried under vacuum and then reconstituted with $300 \mu \mathrm{l}$ of a mixture of methanol $(88 \%) /$ ethanol $(10 \%) /$ hexane $(2 \%)$. In order to correct for recoveries, internal standards (Tocol for the tocopherols; Echinenone for the carotenoids) were run with each sample. In each batch, an external calibration was also performed using the standard solutions at eight different concentrations. Peaks for carotenoids that were under the detection limits were set to zero, whereas peaks that could not be detected because of technical problems were excluded from the study. The detection limits were set at: $0.062 \mu \mathrm{g} \mathrm{dl}^{-1}$ for $\alpha$-carotene, $\beta$-carotene and $\beta$-cryptoxanthin, $0.060 \mu \mathrm{g} \mathrm{dl}^{-1}$ for canthaxanthin, $0.042 \mu \mathrm{g} \mathrm{dl}^{-1}$ for lutein and zeaxanthin, $0.078 \mu \mathrm{g} \mathrm{dl}^{-1}$ for lycopene, $0.074 \mu \mathrm{g} \mathrm{dl}^{-1}$ for retinol and $1.898 \mu \mathrm{g} \mathrm{dl}^{-1}$ for the tocopherols. The coefficients of variation were: $10.1 \%$ for $\alpha$-carotene, $5.5 \%$ for $\beta$-carotene, $6.5 \%$ for $\beta$-cryptoxanthin, $13.6 \%$ for canthaxanthin, $4.3 \%$ for lutein, $7.4 \%$ for retinol, $7.4 \%$ for lycopene, $8.4 \%$ for zeaxanthin, $5.6 \%$ for $\alpha$-tocopherol and $8.4 \%$ for $\alpha$-tocopherol. No significant betweenday drift was observed.

As different carotenoids tend to be, for the most part, present together in various food sources, and as carotenoids may act cumulatively together (Liu, 2004), it was decided to create a variable representing the total sum of the concentration of the seven individual carotenoids analysed, expressed in terms of both weight $\left(\mu \mathrm{g} \mathrm{dl}^{-1}\right)$ and molar equivalents $\left(\mu \mathrm{moll}^{-1}\right)$. The methodology used in the present study allows the separation of lutein and zeaxanthin. As many publications in this field do not separate these analytes, the sum of the concentrations of lutein and zeaxanthin was also calculated for comparison purposes.

In addition, the composition of 22 individual saturated and unsaturated fatty acids was determined in plasma phospholipids by gas chromatography using the method of Chajes et al (1999).

For all analytes, matched case-control sets were assayed in the same batch in order to minimise errors from batch to batch variations. Two quality control samples were run per analysis batch. Laboratory technicians were blinded to the case/control status of all samples.

\section{Statistical methods}

Differences between cases and controls in mean levels for each analyte were tested by paired $t$-tests of the log-transformed value in each case-control set. In addition, Spearman's correlations, adjusted for age, body mass index, total energy intake, smoking status/duration/intensity and Hp positivity, were calculated for the matrix of log-transformed analytes, as well as for the correlation of plasma and dietary $\beta$-carotene, retinol and vitamin $\mathrm{E}$ and the correlation of plasma $\alpha$ - and $\gamma$-tocopherols with total plasma fatty acids and total plasma saturated fatty acids.

Odds ratios (OR) and 95\% confidence intervals (95\% CI) for GC risk in relation to plasma analyte concentrations and for dietary intake levels of dietary $\beta$-carotene, retinol and vitamin $\mathrm{E}$ were calculated by conditional logistic regression (SAS statistical software, version 9, SAS Institute, Cary, NC, USA), stratified by the case-control set. The effects of potential confounders, other than matching criteria, which are controlled for by design, were examined by including additional regression terms into the logistic regression models. Potential confounders included total energy intake (in quartiles), body mass index (quartiles), $\mathrm{Hp}$ infection status (yes/no) and duration/status/intensity of smoking (variable categories: never-smokers, ex-smokers who smoked for $<10$ years, ex-smokers who smoked for $\geqslant 10$ years, smokers who smoke $<15$ cigarettes day ${ }^{-1}$, smokers who smoke between $15-25$ cigarettes day $^{-1}$, smokers who smoke $\geqslant 25$ cigarettes day $^{-1}$ and missing). The effects of age, alcohol intake and the level of schooling (an indicator variable for socioeconomic status) were also examined, but they did not substantially alter the risk estimates and were therefore not included in the final model. The plasma analyte concentrations were examined by quartile categories with cut-points based on the distribution of each specific analyte in the control subjects. For comparison purposes, models for plasma tocopherols were also further adjusted for either plasma total fatty acids or plasma total saturated fatty acids. Results for $\alpha$-tocopherol without an adjustment for plasma fatty acids are referred to here as being 'lipid-unadjusted'.

Models similar to the above were run with analytes included in the model as non-log-transformed continuous variables with the relative risk and $95 \% \mathrm{CI}$ calculated as the risk for a change in the plasma level by 1 s.d. of the mean of all GC control subjects. A similar approach was used for models analysing the dietary variables. For all models, linear trend tests were determined using a score variable with values from 1 to 4 , consistent with the quartile grouping.

All of the above models were also run for the total sum of carotenoids, retinol and $\alpha$-tocopherol by GC anatomical subsite (cardia/noncardia) and histological subtype (diffuse/intestinal). For comparability, the same quartile cut-points used for analysis of all GCs were used in subgroup analyses. As described above, for a number of reasons, some GC cases could not be classified by anatomical subsite or histological subtype. For comparison purposes, ORs were also calculated for these cases and matched 
controls, using the above methods. For all analytes and dietary variables, tests for heterogeneity were performed for comparisons of GCs by subsite and by histological subtype (Rothman and Greenland, 1998).

For all analytes, potential effect modification by gender, Hp infection status and the time to diagnosis of GC of less than 2 years or more than 2 years was tested using the likelihood ratio test to assess the statistical significance of a linear interaction. For the assessment of interaction for time to diagnosis of GC, each control set was assigned the value for years of follow-up of its matched case. No overall significant interactions were observed for any of these variables. However, $\mathrm{Hp}$ infection status was nonetheless placed in the model as a confounding variable because of its potential to alter the systemic bioavailability of antioxidants and affect their concentrations in gastric juice (Zhang et al, 2000; Woodward et al, 2001; Annibale et al, 2002). In addition, to further explore the role of $\mathrm{Hp}$ infection status and smoking status (never, former, current, with missing in a separate category), unmatched case-control analyses stratified by these variables and with each analyte modelled individually as a continuous variable, were performed using unconditional logistic regression models adjusted for matching variables, as well as the laboratory batch and all other adjustment variables described above.

\section{RESULTS}

\section{Baseline characteristics and description of the study population}

The mean age at recruitment of GC cases and controls was 59.1 years (Table 1). On average, GC cases had 3.2 years between blood donation and the time of diagnosis and had a higher percentage of Hp positivity than controls (Table 1). The data set included 137 male cases and 349 controls, and 107 female cases and 296 controls (Table 1). Adjusted Spearman's correlations among the analytes were strongest between $\alpha$ - and $\beta$-carotene $(r=0.70, P<0.001)$, and lutein and zeaxanthin $(r=0.76, P<0.001)$. Retinol was very weakly correlated with individual carotenoids and with the sum of all carotenoids $(r=0.19, P<0.001)$. The correlations between the plasma and dietary values of $\beta$-carotene $(r=0.28, P<0.001)$ and retinol $(r=0.20, P<0.001)$ were modest, whereas that of plasma $\alpha$ plus $\gamma$-tocopherol with dietary vitamin $\mathrm{E}$ (includes tocopherols and tocotrienols) was weak $(r=0.07, P=0.05)$. Plasma $\alpha$-tocopherol was strongly correlated with both total plasma fatty acids $(r=0.46$, $P<0.0001)$ and total plasma saturated fatty acids $(r=0.49$, $P<0.001$ ), whereas the correlations for plasma $\gamma$-tocopherol were weaker ( $r=0.25, P<0.001 ; r=0.31, P<0.001$, respectively).

\section{Gastric cancer}

Table 2 shows the mean value and s.d. in GC cases and controls for all analytes. The mean plasma concentrations of zeaxanthin and retinol, but not any of the other analytes, were significantly lower in cases than controls (Table 2). When considering quartiles of individual analytes in plasma and GC risk, $\beta$-cryptoxanthin $\left(P_{\text {trend }}=0.006\right)$, zeaxanthin $\left(P_{\text {trend }}=0.005\right)$, retinol $\left(P_{\text {trend }}=0.005\right)$ and lipid-unadjusted $\alpha$-tocopherol $\left(P_{\text {trend }}=0.022\right)$ showed significant negative associations at the highest $v s$ the lowest quartiles (Table 3). The results of the effects of the other analytes were not statistically significant (Table 3). When the plasma levels of individual carotenoids were summed $\left(\mu \mathrm{g} \mathrm{dl}^{-1}\right)$, the total variable showed a nonstatistically significant negative association with GC

Table I Baseline characteristics and description of the study population of cases and controls in GCs

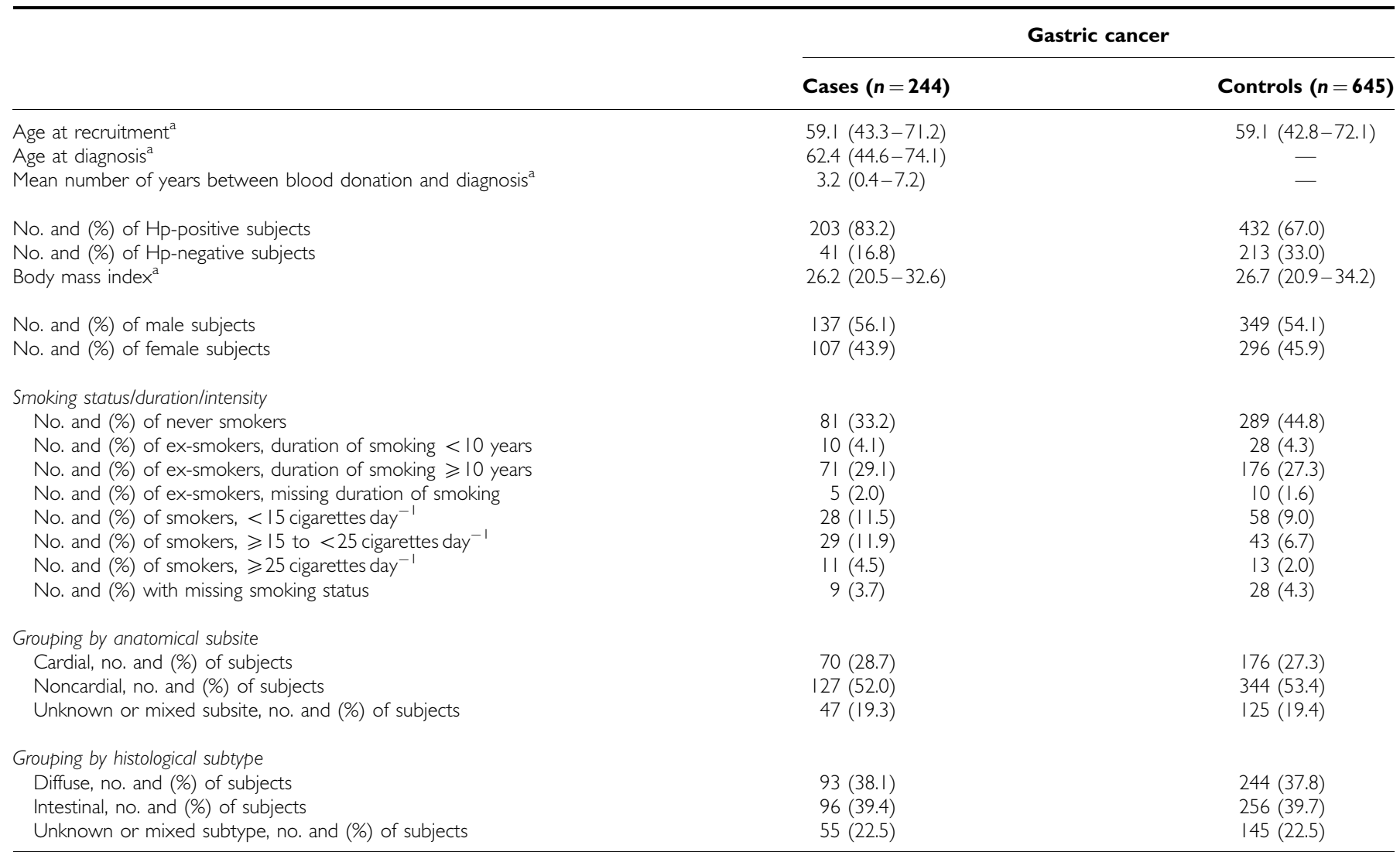

GC, gastric cancer. ${ }^{a}$ Values are means (5th-95th percentile range). Distribution of cases/controls by EPIC country: Denmark $=23 / 39 ;$ France $=3 / 10$; Germany $=30 / 87$; Greece = I2/26; Italy=44/|47; Netherlands = 19/60; Spain =28/85; Sweden = 57/II2 and United Kingdom = 28/79. 
Table 2 Means, s.d. and P-values for a difference between cases and controls for plasma levels of carotenoids, retinol and tocopherols in GCs

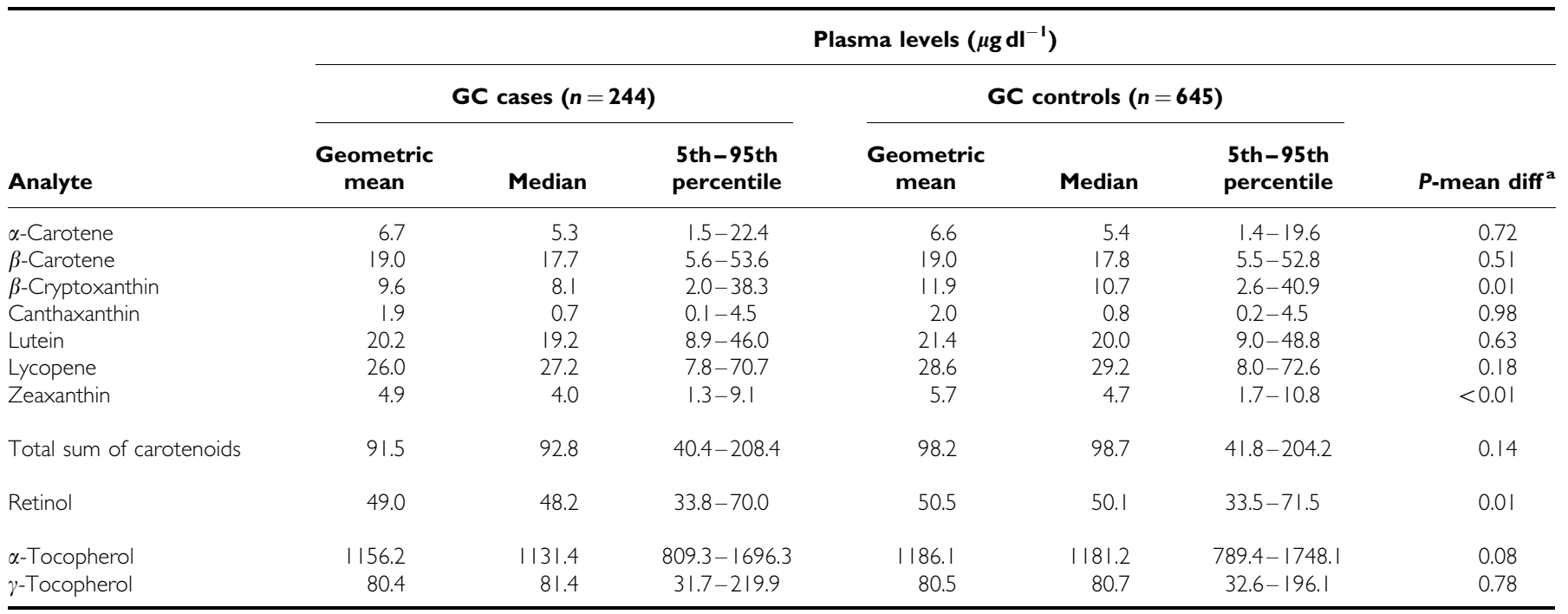

GC, gastric cancer; s.d., standard deviation. ${ }^{2}$ Two-sided $P$-values of paired t-test on log-transformed values given for a difference in means between cases and controls per analyte. For the sum of lutein/zeaxanthin, the mean concentration was $\left.24.2 \mu \mathrm{g} \mathrm{d}\right|^{-1}$ in cases and $\left.26.2 \mu \mathrm{g} \mathrm{d}\right|^{-1}$ in controls, with a P-value for difference of 0.16 .

Table 3 OR for plasma levels of carotenoids, retinol and tocopherols and risk of GCs

OR for quartiles of plasma analyte levels ${ }^{\mathrm{a}}$ category cut-points $\left(\mu \mathrm{g} \mathrm{dl}^{-1}\right)$

\begin{tabular}{|c|c|c|c|c|c|c|}
\hline \multirow[b]{2}{*}{ Analyte } & \multicolumn{4}{|c|}{ OR for quartiles of plasma analyte levels ${ }^{\mathrm{a}}$ category cut-points $\left(\mu \mathrm{g} \mathrm{dl}^{-1}\right)$} & \multirow[b]{2}{*}{$\begin{array}{l}P \text {-value } \\
\text { for trend }\end{array}$} & \multirow{2}{*}{$\begin{array}{c}\text { OR of one I s.d. } \\
\text { increase in plasma levels }\end{array}$} \\
\hline & Ref. & 2 & 3 & 4 & & \\
\hline$\beta$-Carotene & $\begin{array}{r}<12.0 \\
\quad 1.00\end{array}$ & $\begin{array}{l}\geq 12.0 \text { to }<17.8 \\
0.96(0.60-1.79)\end{array}$ & $\begin{array}{l}\geqslant 17.8 \text { to }<26.5 \\
1.09(0.67-1.79)\end{array}$ & $\begin{array}{c}\geqslant 26.5 \\
1.13(0.69-1.86)\end{array}$ & 0.539 & $\begin{array}{c}\left.18.9 \mu \mathrm{g} \mathrm{d}\right|^{-1} \\
1.09(0.94-1.27)\end{array}$ \\
\hline Canthaxanthin & $\begin{array}{l}<0.4 \\
1.00\end{array}$ & $\begin{array}{c}\geqslant 0.4 \text { to }<0.8 \\
0.97(0.61-1.54)\end{array}$ & $\begin{array}{c}\geqslant 0.8 \text { to }<1.6 \\
1.04(0.64-1.71)\end{array}$ & $\begin{array}{c}\geqslant 1.6 \\
0.80(0.44-1.45)\end{array}$ & 0.630 & $\begin{array}{c}1.6 \mu \mathrm{g} \mathrm{dl}-1 \\
1.08(0.84-1.38)\end{array}$ \\
\hline Lutein & $\begin{array}{r}<14.6 \\
\quad 1.00\end{array}$ & $\begin{array}{l}\geqslant 14.6 \text { to }<20.0 \\
1.10(0.69-1.74)\end{array}$ & $\begin{array}{l}\geqslant 20.0 \text { to }<28.9 \\
0.95(0.57-1.56)\end{array}$ & $\begin{array}{c}\geqslant 28.9 \\
0.73(0.43-1.37)\end{array}$ & 0.356 & $\begin{array}{c}\left.13.3 \mu \mathrm{g} \mathrm{d}\right|^{-1} \\
0.93(0.75-1.15)\end{array}$ \\
\hline Zeaxanthin & $\begin{array}{l}<3.2 \\
\quad 1.00\end{array}$ & $\begin{array}{c}\geqslant 3.2 \text { to }<4.7 \\
0.62(0.39-0.99)\end{array}$ & $\begin{array}{c}\geqslant 4.7 \text { to }<6.7 \\
0.68(0.42-1.10)\end{array}$ & $\begin{array}{c}\geqslant 6.7 \\
0.39(0.22-0.70)\end{array}$ & 0.005 & $\begin{array}{c}3.0 \mu \mathrm{g} \mathrm{dl}^{-1} \\
0.65(0.5 \mathrm{I}-0.8 \mathrm{I})\end{array}$ \\
\hline Total sum of carotenoids & $\begin{array}{r}<70.5 \\
\quad 1.00\end{array}$ & $\begin{array}{l}\geqslant 70.5 \text { to }<98.7 \\
0.99(0.62-1.59)\end{array}$ & $\begin{array}{l}\geqslant 98.7 \text { to }<135.9 \\
0.99(0.61-1.59)\end{array}$ & $\begin{array}{c}\geqslant 135.9 \\
0.69(0.39-1.21)\end{array}$ & 0.259 & $\begin{array}{c}50.3 \mu \mathrm{g} \mathrm{dl}^{-1} \\
0.93(0.76-1.13)\end{array}$ \\
\hline Retinol & $\begin{array}{r}<42.4 \\
\quad 1.00\end{array}$ & $\begin{array}{l}\geqslant 42.4 \text { to }<55.9 \\
0.99(0.66-1.54)\end{array}$ & $\begin{array}{l}\geqslant 55.9 \text { to }<63.8 \\
0.55(0.34-0.91)\end{array}$ & $\begin{array}{c}\geqslant 63.8 \\
0.55(0.33-0.93)\end{array}$ & 0.005 & $\begin{array}{c}|2.5 \mu \mathrm{g} \mathrm{d}|^{-1} \\
0.80(0.67-0.97)\end{array}$ \\
\hline$\alpha$-Tocopherol ${ }^{d}$ & $\begin{array}{r}<1022.0 \\
1.00\end{array}$ & $\begin{aligned} \geqslant & 1022.0 \text { to }<1181.2 \\
& 0.62(0.40-0.96)\end{aligned}$ & $\begin{array}{c}\geqslant \mid 181.2 \text { to }<393.7 \\
0.61(0.39-0.96)\end{array}$ & $\begin{array}{c}\geqslant 1393.7 \\
0.59(0.37-0.94)\end{array}$ & 0.022 & $\begin{array}{c}303.2 \mu \mathrm{g} \mathrm{dl} \\
0.90(0.76-1.07)\end{array}$ \\
\hline$\gamma$-Tocopherol ${ }^{e}$ & $\begin{aligned}<52.7 \\
\quad 1.00\end{aligned}$ & $\begin{array}{l}\geqslant 52.7 \text { to }<80.7 \\
1.13(0.69-1.87)\end{array}$ & $\begin{array}{l}\geqslant 80.7 \text { to }<116.7 \\
1.16(0.68-1.99)\end{array}$ & $\begin{array}{c}\geqslant 116.7 \\
1.00(0.56-1.78)\end{array}$ & 0.968 & $\begin{array}{c}50.3 \mu \mathrm{g} \mathrm{d}^{-1} \\
1.09(0.90-1.31)\end{array}$ \\
\hline
\end{tabular}

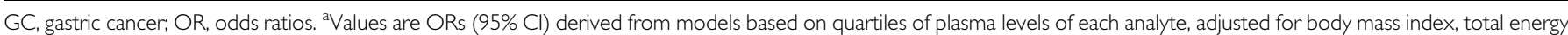
intake, smoking status/duration/intensity and $\mathrm{Hp}$ status. ${ }^{\mathrm{b}} \mathrm{P}$ of $\chi^{2}$ test for trend using a continuous variable with I df. ${ }^{c}$ Values are ORs $(95 \% \mathrm{Cl})$, derived from models as described above, for a risk associated with an increase in plasma carotenoid level equivalent to I s.d. of the mean level of the specific analyte in the controls, as specified in the table for each analyte. ${ }^{\mathrm{d}}$ Results for $\alpha$-tocopherol adjusted by total plasma fatty acids: $\mathrm{Q} 2=0.54(0.34-0.86) ; \mathrm{Q} 3=0.52(0.32-0.86) ; \mathrm{Q} 4=0.48(0.28-0.84) ; P_{\text {trend }}=0.009$. ${ }^{e}$ Results for $\gamma$-tocopherol adjusted by total plasma fatty acids: Q2 = $1.13(0.68-1.87) ; \mathrm{Q} 3=1.13(0.65-1.95) ; \mathrm{Q} 4=1.00(0.55-1.82) ; P_{\text {trend }}=0.959$. 
risk (highest $v s$ lowest quartiles $\mathrm{OR}=0.69,95 \% \mathrm{CI}=0.39-1.21$, $\left.P_{\text {trend }}=0.259\right) \quad$ (Table 3). Calculation of the total sum of carotenoids based on molar equivalents of each carotenoid did not change the GC risk association (highest vs lowest quartiles $\mathrm{OR}=0.71,95 \% \mathrm{CI}=0.41-1.75, P_{\text {trend }}=0.314$, OR for $0.92 \mu \mathrm{moll}^{-1}$ increase in plasma levels $=0.93,95 \% \mathrm{CI}=0.77-1.14$ ).

No significant association with GC risk was observed for the sum of lutein/zeaxanthin. For this variable, the OR (95\% CI) for each quartile $v s$ the lowest were as follows: Q2, $0.97(0.61-1.54)$; Q3, $0.86(0.53-1.42)$ and Q4, $0.71(0.40-1.25)$, with $P_{\text {trend }}=0.229$ (data not shown in Table 3 ). None of the risk estimates were changed by exclusion of the 22 cases and 38 controls who had developed a cancer at a site other than the stomach before enrolment in the cohort.

Adjustment of $\alpha$ - or $\gamma$-tocopherol measures by plasma total fatty acids (Table 3, footnotes) or total saturated fatty acids (data not shown) did not materially change any of the GC risk estimates obtained. Furthermore, in the above subset, comparisons of unconditional logistic regression models ( $n$ cases $=43, n$ controls $=121$ ) adjusted by blood total cholesterol $v s$ plasma total fatty acids or total saturated fatty acids showed no differences in the GC risk associations obtained (data not shown).

H. pylori infection status and smoking status For individual carotenoids, no statistically significant effects or differences in direction/magnitude of the effect were observed by Hp infection status. For the total sum of carotenoids, the results for a $50.3 \mu \mathrm{g} \mathrm{dl}^{-1}$ unit increase (equivalent to the s.d. of the mean of all GC controls) were as follows: (OR $(95 \% \mathrm{CI})) \mathrm{Hp}$ negative: 0.94 (0.60-1.49); Hp positive: $0.90(0.73-1.12)$. For retinol, the ORs for a $12.5 \mu \mathrm{g} \mathrm{dl}^{-1}$ unit increase in plasma levels were as follows: Hp negative: 1.00 (0.66-1.53); Hp positive: $0.73(0.60-0.90)$. For $\alpha$-tocopherol, the ORs for a $303.2 \mu \mathrm{g} \mathrm{dl}^{-1}$ unit increase in plasma levels were: Hp negative: $1.13(0.76-1.66)$, Hp positive: 0.82 (0.67$1.00)$. A similar approach was used to explore any role of smoking status, but no differences were observed for any of the analytes. There was no significant interaction with GC risk between smoking status and any of the analytes, including the carotenes.

Dietary values There were no significant differences between cases and controls in the daily intake of $\beta$-carotene (mean \pm s.e.) (cases: $2.97 \pm 0.15$, controls: $2.92 \pm 0.10 \mathrm{mg} \mathrm{day}^{-1}$ ), retinol (cases: $1.07 \pm 0.07$, controls: $0.92 \pm 0.04 \mathrm{mg} \mathrm{day}^{-1}$ ) and vitamin $\mathrm{E}$ (cases: $10.00 \pm 0.33$, controls: $10.26 \pm 0.20 \mathrm{mg} \mathrm{day}^{-1}$ ). No significant GC risk associations were observed for dietary $\beta$-carotene (OR of 1 s.d. increase in intake of $2.4 \mathrm{mg} \mathrm{day}^{-1}=1.04,95 \% \mathrm{CI}=0.88-1.24$, $\left.P_{\text {trend }}=0.090\right)$, retinol (OR of 1 s.d. increase in intake of $\left.0.89 \mathrm{mg} \mathrm{day}^{-1}=1.10,95 \% \quad \mathrm{CI}=0.93-1.29, \quad P_{\text {trend }}=0.450\right) \quad$ and vitamin $\mathrm{E}$ (OR of 1 s.d. increase in intake of $5.10 \mathrm{mg} \mathrm{day}^{-1}=0.99$, $\left.95 \% \mathrm{CI}=0.81-1.22, \quad P_{\text {trend }}=0.290\right)$. Tests for heterogeneity between anatomical subsites for these dietary variables were not statistically significant ( $\beta$-carotene: $P=0.61$; retinol: $P=0.59$; vitamin E: $P=0.23$ ). Similarly, for grouping by the two histological subtypes, the $P$-values for heterogeneity tests were as follows: $\beta$-carotene: $P=0.39$; retinol: $P=0.42$ and vitamin $\mathrm{E}: P=0.40$. As a result, analyses stratifying for subsite and subtype for the dietary variables were not performed.

\section{Grouping of GC by anatomical subsites}

When explored by cardia or noncardia subsites, there was no evidence that the association between the individual analytes and risk was different. For $\beta$-cryptoxanthin and zeaxanthin, the two individual carotenoids that exhibited the strongest association with GC risk, the $P$-values for tests of heterogeneity between the two subsites were 0.154 and 0.258 , respectively. However, given the potential of GC aetiology to differ by anatomical subsite, subgroup analyses were performed for total sum of carotenoids (test for heterogeneity $P=0.33$ ), retinol (test for heterogeneity $P=0.44$ ) and $\alpha$-tocopherol (test for heterogeneity $P=0.84$ ). No significant negative associations were observed for any of these variables in the cardial or noncardial subsites (Table 4).

For comparison purposes, ORs for groups of cases $(n=47, \mathrm{n}$ matched controls $=125$ ) of unknown or mixed anatomical subsites were also calculated for each of the above analytes modelled as continuous variables with a risk estimate for a unit increase equivalent to the s.d. of the mean value of the analyte in all GC controls: (i) for total sum of carotenoids, the OR (95\% CI) for a unit increase of $50.3 \mu \mathrm{g} \mathrm{dl}^{-1}$ was $0.84(0.52-1.38)$, (ii) for retinol, the OR for a unit increase of $12.5 \mu \mathrm{g} \mathrm{dl}^{-1}$ was $0.37(0.19-0.71)$ and (iii) for $\alpha$-tocopherol, the OR for a unit increase of $303.2 \mu \mathrm{g} \mathrm{dl}^{-1}$ was $0.58(0.36-0.93)$.

\section{Grouping of GC by histological subtypes}

When explored by diffuse and intestinal histological subtypes, there was no evidence that the association with risk in the two subtypes was different for individual carotenoids. Neither the total sum of carotenoids $(P$ heterogeneity $=0.19)$ nor retinol $(P$ heterogeneity $=0.10)$ showed any significant associations with GC risk in either the diffuse or intestinal subtypes (Table 4). However, $\alpha$-tocopherol $(P$ heterogeneity $=0.02)$ showed a significant inverse association with the diffuse subtype at the highest quartile of plasma concentrations $v s$ the lowest $(\mathrm{OR}=0.26,95 \%$ $\left.\mathrm{CI}=0.11-0.65, P_{\text {trend }}=0.003\right)($ Table 4$)$.

For comparison purposes, ORs for groups of cases $(n=55, n$ matched controls $=145$ ) of unknown or mixed histological subtypes were also calculated for each of the above analytes, modelled as continuous variables with a risk estimate for a unit increase equivalent to the s.d. of the mean value of the analyte in all GC controls: (i) for total sum of carotenoids, the OR (95\% CI) for a unit increase of $50.3 \mu \mathrm{g} \mathrm{dl}^{-1}$ was $0.86(0.57-1.29)$, (ii) for retinol, the OR for a unit increase of $12.5 \mu \mathrm{g} \mathrm{dl}^{-1}$ was $0.52(0.32-$ 0.86 ) and (iii) for $\alpha$-tocopherol, the OR for a unit increase of $303.2 \mu \mathrm{g} \mathrm{dl}^{-1}$ was $0.92(0.67-1.25)$.

\section{DISCUSSION}

The results of this large, nested case-control study show that higher plasma concentrations of some individual carotenoids ( $\beta$-cryptoxanthin, zeaxanthin), retinol and $\alpha$-tocopherol are associated with a significant lower risk of developing GC during the follow-up period.

Carotenoids and tocopherols have been suggested to be cancer preventive mainly because of their antioxidant properties, which may lead to a reduction in the extent of oxidative stress, lipid peroxidation and DNA damage, whereas retinol, along with the provitamin A carotenoids, is involved in the control of cellular growth kinetics (Sporn and Roberts, 1983). Despite this potential, results from previous reports on dietary intake of carotenoids assessed from dietary questionnaires have been mixed and many have not shown strong associations with GC risk (Chyou et al, 1990; Zheng et al, 1995; Botterweck et al, 2000b). To date, only a few studies have considered prediagnostic blood levels of carotenoids in association with GC risk. A small Japanese study found no association between GC risk and blood levels of retinol, $\beta$-carotene or $\alpha$-tocopherol, but did not consider anatomical subsite or histological subtype (Nomura et al, 1995). Larger studies, set in high-risk Chinese populations, show either (i) a borderline significant negative association between retinol and GCs of the cardia, and between $\beta$-cryptoxanthin and noncardial GC, and an increased risk of noncardial GC with higher levels of lutein/ zeaxanthin (Abnet et al, 2003) or (ii) an inverse effect of $\alpha$ - and $\beta$-carotene and lycopene on GC risk, but without consideration of anatomical subsite or histological subtypes (Yuan et al, 2004). 
Table 4 OR for plasma levels of total sum of carotenoids, retinol and $\alpha$-tocopherol and the risk of GCs by anatomical subsite and histological subtype

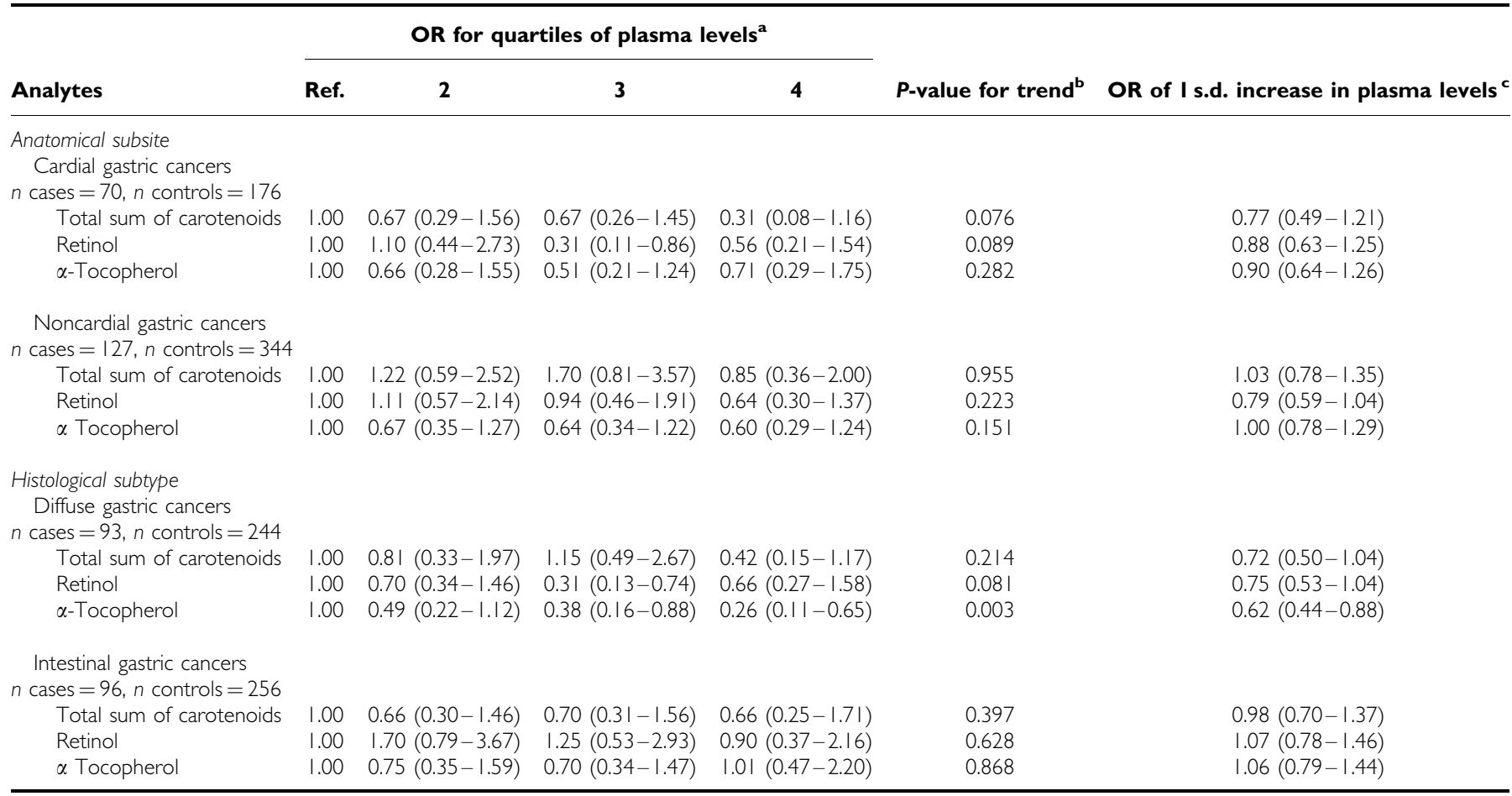

GC, gastric cancer; OR, odds ratios. ${ }^{a}$ Values are ORs derived from models described above based on quartiles of plasma levels of each analyte. Analyte specific quartile cut-points are as listed on Table 3. ${ }^{b} \mathrm{P}$ of $\chi^{2}$ test for trend using a continuous variable with I df. ${ }^{c}$ Values are ORs ( $95 \% \mathrm{Cl}$ ), derived from models as described above, for a risk associated with an increase in plasma carotenoid level equivalent to I s.d. of the mean level of the specific analyte in all $\mathrm{GC}$ controls $\left(\mu \mathrm{g} \mathrm{dl}^{-1}\right)$ : total carotenoids $=50.3$; retinol $=12.5$ and tocopherol $=303.2$.

Most of the current literature on carotenoids and GC risk is focused on $\beta$-carotene (Correa et al, 1998). This study did not observe any association with plasma levels of $\alpha$ - or $\beta$-carotene and GC risk, whereas previous prospective studies have shown lower plasma levels of $\beta$-carotene in GC cancer cases $v s$ controls in a Western population (Eichholzer et al, 1996) and either an inverse association (Yuan et al, 2004), no association (Abnet et al, 2003) or a positive association (You et al, 2000) with GC risk in high-risk Chinese populations. Intervention studies with $\beta$-carotene, however, have shown no effect on GC risk in low-risk populations (Hennekens et al, 1996), and either no effect (Varis et al, 1998) or mild protective effects in high-risk populations (Blot et al, 1995; Correa et al, 2000). In the present study, no GC risk associations were observed for dietary $\beta$-carotene and in a concurrent study of fruit and vegetable intake based on the entire EPIC cohort, no GC risk association was observed with the intake of fruiting and root vegetables (Gonzalez et al, 2006), which are good sources of carotenes (Al Delaimy et al, 2005a). Taken together, these observations suggest that any protective effects of the carotenes, or carotenoids in general, are likely to be small.

The present study did not observe any statistically significant inverse associations with blood levels of lycopene, which is obtained predominantly from tomatoes and tomato-based products. Blood lycopene levels have previously been shown to be associated with an inverse GC risk (Yuan et al, 2004), but this was in a high-risk Chinese population with low baseline lycopene levels. It may be that, given the higher tomato consumption in Western populations, both cases and controls in the present study were above a threshold of lycopene effect levels.

Dietary lutein, zeaxanthin and $\beta$-cryptoxanthin, which belong to the xanthophyll family of carotenoids and are found mostly in corn, leafy green vegetables and citrus fruits, have been shown to have no association with GC risk in ecological (Tsubono et al, 1999), case-control (Garcia-Closas et al, 1999; Chen et al, 2002) and cohort (Botterweck et al, 2000b) studies. In a concurrent study of fruit and vegetable intake based on the entire EPIC cohort, a negative GC risk association was observed with the intake of citrus fruits, some members of which are good sources of these carotenoids (Gonzalez et al, 2006). Only two studies to date, both in high-risk Chinese populations, have considered prediagnostic blood levels of these carotenoids. One (Yuan et al, 2004) found no risk association, whereas the other (Abnet et al, 2003) showed a significant increased risk of noncardial GC with high intake of lutein and zeaxanthin.

In general, retinol, which is mostly derived from animal sources, has not previously been associated with GC risk in a prospective setting (Abnet et al, 2003; Yuan et al, 2004; Nouraie et al, 2005). However, in the present study, higher plasma retinol was associated with a lower risk of GC. Its potential involvement in important processes of carcinogenesis, namely cell differentiation, adhesion and membrane permeability (van Poppel and van den Berg, 1997), imply that it may have a role in cancer prevention. Although these observations are encouraging, they require further confirmation and validation.

Previous results from prospective studies analysing blood $\alpha$ tocopherol levels are conflicting, probably because they are reflective of differences in the various populations analysed. For example, in different high-risk Chinese populations, higher blood $\alpha$-tocopherol has been shown to have either a nonstatistically significant (Yuan et al, 2004) or borderline significant (You et al, 2000 ) positive association with GC risk, or to be associated with a marginal decreased risk of cardial GC and an increased risk of noncardial GC (Taylor et al, 2003). Conversely, in a Finnish population of smokers, higher baseline blood $\alpha$-tocopherol has been associated with a marginally significant increase in the risk of cardial GC (Nouraie et al, 2005). In the present study, higher plasma $\alpha$-tocopherol level was negatively associated with GC risk. 
It is also important to note that the plasma tocopherol results presented here are lipid-unadjusted. Some (Taylor et al, 2003; Nouraie et al, 2005) but not all (You et al, 2000; Yuan et al, 2004) of the above studies adjusted their blood tocopherol measures for blood total cholesterol in order to correct for possible confounding, as tocopherols are transported in the blood as part of lipoprotein complexes (Willett, 1998). In the present study, this adjustment was not possible as data on blood total cholesterol values exist for only a subset of subjects. However, data on plasma total fatty acids and total saturated fatty acids do exist for all subjects. They may serve as surrogates for blood total cholesterol because, in the subset of subjects described above, blood total cholesterol was correlated with plasma total fatty acids $(P=0.46$, $P<0.001)$ and total saturated fatty acids $(P=0.44, P<0.001)$, whereas $\alpha$-tocopherol was correlated with plasma total fatty acids $(P=0.50, P<0.001)$, total saturated fatty acids $(P=0.48, P<0.001)$ and blood total cholesterol $(P=0.50, P<0.001)$, which is in line with previous observations (Willett et al, 1983). Adjustments of plasma tocopherol measures for plasma total fatty acids or total saturated fatty acids did not materially alter the GC risk estimates obtained.

In the present study, no GC risk associations were observed for increasing dietary intakes of retinol and vitamin E, whereas their plasma measures showed significant negative GC risk associations in the highest quartiles. This observed difference in effect may suggest inaccuracies in the measured dietary values, perhaps owing to measurement errors in assessment of intake, errors in food composition tables or the lack of information on intake from dietary supplements. However, it is also true that measures of dietary intake, no matter how accurate, do not reflect the bioavailability of the nutrients from various foods, the level of absorption from the digestive tract or individual metabolising differences, which are key in determining blood concentrations of these nutrients. These results highlight the importance of measuring blood biomarkers of intake in addition to dietary intake levels.

The key advantage of the present study, aside from its prospective design, is its ability to differentiate GCs by anatomical subsite and histological subtype according to classifications made by a team of expert pathologists. Of the previous studies, all of them case-control, that have considered GC pathology in relation to dietary carotenoids, some have failed to detect any associations or differences by subtype (Boeing et al, 1991; Buiatti et al, 1991), whereas others have shown mixed results (Gonzalez et al, 1994; Harrison et al, 1997; Ekstrom et al, 2000), suggesting that the effects of carotenoids might be similar in both histological subtypes. In the present study, none of the analytes, with the possible exception of $\alpha$-tocopherol, showed any significant effects by anatomical subsite or histological subtype. As data from previous prospective studies on the effect of these analytes on groupings of subsite and subtype are scarce, and the present findings are based on a small number of cases, confirmation with better-powered studies is necessary.

One of the key limitations of the present study may be the relatively short follow-up time. Cases identified within a short period after the start of the study may have suffered from some symptoms, leading to dietary changes and hence alterations in the blood carotenoid levels. In order to assess this, interaction tests were run to determine if an effect modification existed with followup time less than or equal to 2 years $v s$ more than 2 years - none was found for any of the analytes. This may suggest that in this study, cases diagnosed close to study entry were not different from those diagnosed later. However, given the long-term nature of GC development and the relatively short follow-up time, some caution is necessary in the interpretation of the results of the present study. Another shortfall of this study is that the variable for total carotenoids was estimated as a simple sum of all carotenoid concentrations and thus does not account for factors such as differences in antioxidative activity or other similar factors that may affect their relative effects.

H. pylori positivity is a major GC risk factor for both the diffuse and intestinal histological subtypes (Parsonnet et al, 1991; Hansson et al, 1993a, b) and may alter systemic carotenoid levels or their secretion patterns into the gastric juice (Zhang et al, 2000; Annibale et al, 2002). In this study, no effect modification by $\mathrm{Hp}$ status at baseline was observed, either because there is no such modification or owing to the fact that a large percentage of cases and controls were $\mathrm{Hp}$ positive. Although the results, with the possible exception of $\alpha$-tocopherol, do not show a difference of effect based on $\mathrm{Hp}$ infection status, better powered studies are called for.

Gastric cancer is known to be one of the many tobacco-related cancers (Gonzalez et al, 2003), which have collectively been shown to be modified by dietary $\beta$-carotene intake and smoking status (Touvier et al, 2005). However, in the present study, no interaction with GC risk was observed between smoking status and any of the analytes, including $\beta$-carotene.

In summary, these results from the EPIC study show that plasma levels of some individual carotenoids, retinol and $\alpha$-tocopherol are inversely associated with GC cancers, irrespective of $\mathrm{Hp}$ status. The protective associations observed were similar for the cardia and noncardia subsites, although the association for $\alpha$-tocopherol may be stronger in the diffuse histological subtype than in the intestinal one. This study has been a comprehensive analysis of many analytes and outcomes. Even though there is reason, based on the antioxidant properties of carotenoids and tocopherols, and the role of retinol in cellular growth kinetics, to believe that the findings presented here may be real, scepticism is merited and a need exists for the confirmation of these results in other prospective settings.

\section{ACKNOWLEDGEMENTS}

We thank the members of the pathologist panel for their valuable work: Dr Roger Stenling, Umea, Sweden; Dr Johan Offerhaus, Amsterdam The Netherlands; Dr Vicki Save, Cambridge, UK; Dr Julio Torrado, San Sebastian, Spain; Dr Gabriella Nesi, Firenze, Italy; Dr U Mahlke, Postdam, Germany; Dr Hendrik Bläker, Heildelberg; Germany; Dr Claus Fenger, Denmark and Dr Dimitrious Roukos, Ioannina, Greece, for his collaboration in the collection of pathological material and Catia Moutinho, Porto, Portugal, for her technical work in the preparation of pathological material.

Specific study results of the nested case-control study within EPIC (EUR-GAST) were obtained with financial support from the FP5 of the European Commission (QLG1-CT-2001-01049).

The EPIC study was funded by 'Europe Against Cancer' Programme of the European Commission (SANCO); Ligue contre le Cancer (France); Société 3M (France); Mutuelle Générale de l'Education Nationale; Institut National de la Santé et de la Recherche Médicale (INSERM); German Cancer Aid; German Cancer Research Center; German Federal Ministry of Education and Research; Danish Cancer Society; Health Research Fund (FIS) of the Spanish Ministry of Health (RCESP-C03/09); the Participating Regional Governments and Institutions of Spain; he ISCIII Red de Centro RCESP (C03/09); Cancer Research UK; Medical Research Council, UK; the Stroke Association, UK; British Heart Foundation; Department of Health, UK; Food Standards Agency, UK; the Wellcome Trust, UK; Greek Ministry of Health; Greek Ministry of Education; Italian Association for Research on Cancer; Italian National Research Council; Compagnia di San Paolo; Dutch Ministry of Public Health, Welfare and Sports; Dutch Ministry of Health; Dutch Prevention Funds; LK Research Funds; Dutch ZON (Zorg Onderzoek Nederland); World Cancer Research Fund (WCRF); Swedish Cancer Society; Swedish Scientific Council; Regional Government of Skane, Sweden and Norwegian Cancer Society. 


\section{REFERENCES}

Abnet CC, Qiao YL, Dawsey SM, Buckman DW, Yang CS, Blot WJ, Dong ZW, Taylor PR, Mark SD (2003) Prospective study of serum retinol, beta-carotene, beta-cryptoxanthin, and lutein/zeaxanthin and esophageal and gastric cancers in China. Cancer Causes Control 14: 645-655

Al Delaimy WK, Ferrari P, Slimani N, Pala V, Johansson I, Nilsson S, Mattisson I, Wirfalt E, Galasso $R$, Palli D, Vineis $P$, Tumino $R$, Dorronsoro M, Pera G, Ocke MC, Bueno-De-Mesquita HB, Overvad K, Chirlaque M, Trichopoulou A, Naska A, Tjonneland A, Olsen A, Lund E, Alsaker EH, Barricarte A, Kesse E, Boutron-Ruault MC, Clavel-Chapelon F, Key TJ, Spencer E, Bingham S, Welch AA, Sanchez-Perez MJ, Nagel G, Linseisen J, Quiros JR, Peeters PH, van Gils CH, Boeing H, van Kappel AL, Steghens JP, Riboli E (2005a) Plasma carotenoids as biomarkers of intake of fruits and vegetables: individual-level correlations in the European Prospective Investigation into Cancer and Nutrition (EPIC). Eur J Clin Nutr 59: $1387-1396$

Al Delaimy WK, Slimani N, Ferrari P, Key T, Spencer E, Johansson I, Johansson G, Mattisson I, Wirfalt E, Sieri S, Agudo A, Celentano E, Palli D, Sacerdote C, Tumino R, Dorronsoro M, Ocke MC, Bueno-De-Mesquita HB, Overvad K, Chirlaque MD, Trichopoulou A, Naska A, Tjonneland A, Olsen A, Lund E, Skeie G, Ardanaz E, Kesse E, Boutron-Ruault MC, Clavel-Chapelon F, Bingham S, Welch AA, Martinez-Garcia C, Nagel G, Linseisen J, Quiros JR, Peeters PH, van Gils CH, Boeing H, van Kappel AL, Steghens JP, Riboli E (2005b) Plasma carotenoids as biomarkers of intake of fruits and vegetables: ecological-level correlations in the European Prospective Investigation into Cancer and Nutrition (EPIC). Eur J Clin Nutr 59: 1397 - 1408

Annibale B, Capurso G, Delle FG (2002) Consequences of Helicobacter pylori infection on the absorption of micronutrients. Dig Liver Dis 34(Suppl 2): S72-S77

Blot WJ, Li JY, Taylor PR, Guo W, Dawsey SM, Li B (1995) The Linxian trials: mortality rates by vitamin-mineral intervention group. Am J Clin Nutr 62: $1424 \mathrm{~S}-1426 \mathrm{~S}$

Boeing H, Jedrychowski W, Wahrendorf J, Popiela T, Tobiasz-Adamczyk B, Kulig A (1991) Dietary risk factors in intestinal and diffuse types of stomach cancer: a multicenter case-control study in Poland. Cancer Causes Control 2: $227-233$

Botterweck AA, Schouten LJ, Volovics A, Dorant E, van Den Brandt PA (2000a) Trends in incidence of adenocarcinoma of the oesophagus and gastric cardia in ten European countries. Int $J$ Epidemiol 29: $645-654$

Botterweck AA, van Den Brandt PA, Goldbohm RA (2000b) Vitamins, carotenoids, dietary fiber, and the risk of gastric carcinoma: results from a prospective study after 6.3 years of follow-up. Cancer 88: 737-748

Buiatti E, Palli D, Bianchi S, Decarli A, Amadori D, Avellini C, Cipriani F, Cocco P, Giacosa A, Lorenzini L, Marubini E, Puntoni R, Saragoni A, Fraumeni Jr JF, Blot WJ (1991) A case-control study of gastric cancer and diet in Italy. III. Risk patterns by histologic type. Int J Cancer 48: $369-374$

Buiatti E, Palli D, Decarli A, Amadori D, Avellini C, Bianchi S, Bonaguri C, Cipriani F, Cocco P, Giacosa A, Marubini E, Minacci C, Puntoni R, Russo A, Vindigni C, Fraumeni Jr JF, Blot WJ (1990) A case-control study of gastric cancer and diet in Italy: II. Association with nutrients. Int $J$ Cancer 45: 896-901

Chajes V, Hulten K, van Kappel AL, Winkvist A, Kaaks R, Hallmans G, Lenner P, Riboli E (1999) Fatty-acid composition in serum phospholipids and risk of breast cancer: an incident case-control study in Sweden. Int J Cancer 83: $585-590$

Chen H, Tucker KL, Graubard BI, Heineman EF, Markin RS, Potischman NA, Russell RM, Weisenburger DD, Ward MH (2002) Nutrient intakes and adenocarcinoma of the esophagus and distal stomach. Nutr Cancer 42: $33-40$

Chyou PH, Nomura AM, Hankin JH, Stemmermann GN (1990) A casecohort study of diet and stomach cancer. Cancer Res 50: $7501-7504$

Corley DA, Kubo A (2004) Influence of site classification on cancer incidence rates: an analysis of gastric cardia carcinomas. J Natl Cancer Inst 96: $1383-1387$

Correa P, Fontham ET, Bravo JC, Bravo LE, Ruiz B, Zarama G, Realpe JL, Malcom GT, Li D, Johnson WD, Mera R (2000) Chemoprevention of gastric dysplasia: randomized trial of antioxidant supplements and anti-Helicobacter pylori therapy. J Natl Cancer Inst 92: 1881-1888

Correa P, Malcom G, Schmidt B, Fontham E, Ruiz B, Bravo JC, Bravo LE, Zarama G, Realpe JL (1998) Review article: antioxidant micronutrients and gastric cancer. Aliment Pharmacol Ther 12(Suppl 1): 73-82
Correa P, Shiao YH (1994) Phenotypic and genotypic events in gastric carcinogenesis. Cancer Res 54: 1941s-1943s

Donaldson MS (2004) Nutrition and cancer: a review of the evidence for an anti-cancer diet. Nutr J 3: 19

Eichholzer M, Stahelin HB, Gey KF, Ludin E, Bernasconi F (1996) Prediction of male cancer mortality by plasma levels of interacting vitamins: 17-year follow-up of the prospective Basel study. Int J Cancer 66: $145-150$

Ekstrom AM, Serafini M, Nyren O, Hansson LE, Ye W, Wolk A (2000) Dietary antioxidant intake and the risk of cardia cancer and noncardia cancer of the intestinal and diffuse types: a population-based casecontrol study in Sweden. Int J Cancer 87: 133-140

Engel LS, Chow WH, Vaughan TL, Gammon MD, Risch HA, Stanford JL, Schoenberg JB, Mayne ST, Dubrow R, Rotterdam H, West AB, Blaser M, Blot WJ, Gail MH, Fraumeni Jr JF (2003) Population attributable risks of esophageal and gastric cancers. J Natl Cancer Inst 95: 1404-1413

Garcia-Closas R, Gonzalez CA, Agudo A, Riboli E (1999) Intake of specific carotenoids and flavonoids and the risk of gastric cancer in Spain. Cancer Causes Control 10: $71-75$

Gonzalez CA, Pera G, Agudo A, Bueno-De-Mesquita HB, Ceroti M, Boeing H, Schulz M, Del Giudice G, Plebani M, Carneiro F, Berrino F, Sacerdote C, Tumino R, Panico S, Berglund G, Siman H, Hallmans G, Stenling R, Martinez C, Dorronsoro M, Barricarte A, Navarro C, Quiros JR, Allen N, Key TJ, Bingham S, Day NE, Linseisen J, Nagel G, Overvad K, Jensen MK, Olsen A, Tjonneland A, Buchner FL, Peeters PH, Numans ME, ClavelChapelon F, Boutron-Ruault MC, Roukos D, Trichopoulou A, Psaltopoulou T, Lund E, Casagrande C, Slimani N, Jenab M, Riboli E (2006) Fruit and vegetable intake and the risk of stomach and oesophagus adenocarcinoma in the European Prospective Investigation into Cancer and Nutrition (EPIC-EURGAST). Int J Cancer 118: 2559-2566

Gonzalez CA, Pera G, Agudo A, Palli D, Krogh V, Vineis P, Tumino R, Panico S, Berglund G, Siman H, Nyren O, Agren A, Martinez C, Dorronsoro M, Barricarte A, Tormo MJ, Quiros JR, Allen N, Bingham S, Day N, Miller A, Nagel G, Boeing H, Overvad K, Tjonneland A, BuenoDe-Mesquita HB, Boshuizen HC, Peeters P, Numans M, Clavel-Chapelon F, Helen I, Agapitos E, Lund E, Fahey M, Saracci R, Kaaks R, Riboli E (2003) Smoking and the risk of gastric cancer in the European Prospective Investigation into Cancer and Nutrition (EPIC). Int J Cancer 107: $629-634$

Gonzalez CA, Riboli E, Badosa J, Batiste E, Cardona T, Pita S, Sanz JM, Torrent M, Agudo A (1994) Nutritional factors and gastric cancer in Spain. Am J Epidemiol 139: 466-473

Hankinson SE, London SJ, Chute CG, Barbieri RL, Jones L, Kaplan LA, Sacks FM, Stampfer MJ (1989) Effect of transport conditions on the stability of biochemical markers in blood. Clin Chem 35: 2313-2316

Hansson LE, Engstrand L, Nyren O, Evans Jr DJ, Lindgren A, Bergstrom R, Andersson B, Athlin L, Bendtsen O, Tracz P (1993a) Helicobacter pylori infection: independent risk indicator of gastric adenocarcinoma. Gastroenterology 105: $1098-1103$

Hansson LE, Nyren O, Bergstrom R, Wolk A, Lindgren A, Baron J, Adami HO (1994) Nutrients and gastric cancer risk. A population-based case-control study in Sweden. Int J Cancer 57: 638-644

Hansson LE, Sparen P, Nyren O (1993b) Increasing incidence of both major histological types of esophageal carcinomas among men in Sweden. Int J Cancer 54: $402-407$

Harrison LE, Zhang ZF, Karpeh MS, Sun M, Kurtz RC (1997) The role of dietary factors in the intestinal and diffuse histologic subtypes of gastric adenocarcinoma: a case - control study in the US. Cancer 80: 1021-1028

Hennekens CH, Buring JE, Manson JE, Stampfer M, Rosner B, Cook NR, Belanger C, LaMotte F, Gaziano JM, Ridker PM, Willett W, Peto R (1996) Lack of effect of long-term supplementation with beta carotene on the incidence of malignant neoplasms and cardiovascular disease. $N$ Engl J Med 334: 1145 - 1149

Kelley JR, Duggan JM (2003) Gastric cancer epidemiology and risk factors. J Clin Epidemiol 56: 1 -9

Key T, Oakes S, Davey G, Moore J, Edmond LM, McLoone UJ, Thurnham DI (1996) Stability of vitamins A, C, and E, carotenoids, lipids, and testosterone in whole blood stored at 4 degrees $\mathrm{C}$ for 6 and $24 \mathrm{~h}$ before separation of serum and plasma. Cancer Epidemiol Biomarkers Prev 5: $811-814$

Lauren PA, Nevalainen TJ (1993) Epidemiology of intestinal and diffuse types of gastric carcinoma. A time-trend study in Finland with comparison between studies from high- and low-risk areas. Cancer 71: 2926-2933 
Liu RH (2004) Potential synergy of phytochemicals in cancer prevention: mechanism of action. J Nutr 134: $3479 \mathrm{~S}-3485 \mathrm{~S}$

Nomura AM, Stemmermann GN, Chyou PH (1995) Gastric cancer among the Japanese in Hawaii. Jpn J Cancer Res 86: 916-923

Nouraie M, Pietinen P, Kamangar F, Dawsey SM, Abnet CC, Albanes D, Virtamo J, Taylor PR (2005) Fruits, vegetables, and antioxidants and risk of gastric cancer among male smokers. Cancer Epidemiol Biomarkers Prev 14: $2087-2092$

Ocke MC, Kromhout D, Menotti A, Aravanis C, Blackburn H, Buzina R, Fidanza F, Jansen A, Nedeljkovic S, Nissienen A, Pekkarinen M, Toshima $\mathrm{H}$ (1995) Average intake of anti-oxidant (pro)vitamins and subsequent cancer mortality in the 16 cohorts of the Seven Countries Study. Int J Cancer 61: $480-484$

Palli D, Masala G, Del Giudice G, Plebani M, Basso D, Berti D, Numans ME, Ceroti M, Peeters PHM, Bueno de Mesquita HB, Clavel-Chapelon F, Krogh V, Saieva C, Vineis P, Panico S, Tumino R, Siman H, Berglund G, Hallmans G, Martinez C, Quiros JR, Navarro C, Key T, Bingham S, Boeing H, Linseisen J, Overvad K, Tjonneland A, Trichoupoulou A, Pera G, Nesi G, Carneiro F, Riboli E, Gonzalez CA (2006) CagA+Helicobacter pylori infection, pepsinogen levels and gastric cancer risk in the European Prospective Investigation into Cancer and Nutrition (EPICEUR-GAST). Gastroenterology (in review)

Parsonnet J, Friedman GD, Vandersteen DP, Chang Y, Vogelman JH, Orentreich N, Sibley RK (1991) Helicobacter pylori infection and the risk of gastric carcinoma. $N$ Engl J Med 325: 1127-1131

Riboli E, Hunt KJ, Slimani N, Ferrari P, Norat T, Fahey M, Charrondiere UR, Hemon B, Casagrande C, Vignat J, Overvad K, Tjonneland A, ClavelChapelon F, Thiebaut A, Wahrendorf J, Boeing H, Trichopoulos D, Trichopoulou A, Vineis P, Palli D, Bueno-De-Mesquita HB, Peeters PH, Lund E, Engeset D, Gonzalez CA, Barricarte A, Berglund G, Hallmans G, Day NE, Key TJ, Kaaks R, Saracci R (2002) European Prospective Investigation into Cancer and Nutrition (EPIC): study populations and data collection. Public Health Nutr 5: 1113-1124

Riboli E, Kaaks R (1997) The EPIC Project: rationale and study design. European Prospective Investigation into Cancer and Nutrition. Int $J$ Epidemiol 26(Suppl 1): S6-S14

Riboli E, Norat T (2003) Epidemiologic evidence of the protective effect of fruit and vegetables on cancer risk. Am J Clin Nutr 78: 559S-569S

Rothman KJ, Greenland S (eds) (1998) Introduction to stratified analysis. In Modern Epidemiology, 2nd edn, pp 53-79. Philadelphia, USA: Lippincott-Raven

Sporn MB, Roberts AB (1983) Role of retinoids in differentiation and carcinogenesis. Cancer Res 43: 3034-3040

Stahelin HB, Gey KF, Eichholzer M, Ludin E, Bernasconi F, Thurneysen J, Brubacher G (1991) Plasma antioxidant vitamins and subsequent cancer mortality in the 12-year follow-up of the prospective Basel Study. Am J Epidemiol 133: 766 - 775

Steghens JP, van Kappel AL, Riboli E, Collombel C (1997) Simultaneous measurement of seven carotenoids, retinol and alpha-tocopherol in serum by high-performance liquid chromatography. J Chromatogr $B$ 694: $71-81$

Taylor PR, Qiao YL, Abnet CC, Dawsey SM, Yang CS, Gunter EW, Wang W, Blot WJ, Dong ZW, Mark SD (2003) Prospective study of serum vitamin E levels and esophageal and gastric cancers. J Natl Cancer Inst 95: $1414-1416$

Touvier M, Kesse E, Clavel-Chapelon F, Boutron-Ruault MC (2005) Dual Association of beta-carotene with risk of tobacco-related cancers in a cohort of French women. J Natl Cancer Inst 97: 1338-1344

Tsubono Y, Tsugane S, Gey KF (1999) Plasma antioxidant vitamins and carotenoids in five Japanese populations with varied mortality from gastric cancer. Nutr Cancer 34: 56-61

van Poppel G, van den Berg H (1997) Vitamins and cancer. Cancer Lett 114: $195-202$

Varis K, Taylor PR, Sipponen P, Samloff IM, Heinonen OP, Albanes D, Harkonen M, Huttunen JK, Laxen F, Virtamo J (1998) Gastric cancer and premalignant lesions in atrophic gastritis: a controlled trial on the effect of supplementation with alpha-tocopherol and beta-carotene. The Helsinki Gastritis Study Group. Scand J Gastroenterol 33: 294-300

Willett W (1998) Nutritional Epidemiology 3 2nd edn. New York, NY: Oxford University Press

Willett WC, Polk BF, Underwood BA, Stampfer MJ, Pressel S, Rosner B, Taylor JO, Schneider K, Hames CG (1984) Relation of serum vitamins A and $\mathrm{E}$ and carotenoids to the risk of cancer. N Engl J Med 310: 430-434

Willett WC, Stampfer MJ, Underwood BA, Speizer FE, Rosner B, Hennekens CH (1983) Validation of a dietary questionnaire with plasma carotenoid and alpha-tocopherol levels. Am J Clin Nutr 38: 631 - 639

Woodward M, Tunstall-Pedoe H, McColl K (2001) Helicobacter pylori infection reduces systemic availability of dietary vitamin C. Eur J Gastroenterol Hepatol 13: 233 - 237

World Cancer Research Fund (1997) Food Research and the Prevention of Cancer: A Global Perspective. Washington, DC: American Institute for Cancer Research

You WC, Zhang L, Gail MH, Chang YS, Liu WD, Ma JL, Li JY, Jin ML, $\mathrm{Hu}$ YR, Yang CS, Blaser MJ, Correa P, Blot WJ, Fraumeni Jr JF, Xu GW (2000) Gastric dysplasia and gastric cancer: Helicobacter pylori, serum vitamin $\mathrm{C}$, and other risk factors. J Natl Cancer Inst 92: $1607-1612$

Yuan JM, Ross RK, Gao YT, Qu YH, Chu XD, Yu MC (2004) Prediagnostic levels of serum micronutrients in relation to risk of gastric cancer in Shanghai, China. Cancer Epidemiol Biomarkers Prev 13: $1772-1780$

Zhang ZW, Patchett SE, Perrett D, Domizio P, Farthing MJ (2000) Gastric alpha-tocopherol and beta-carotene concentrations in association with Helicobacter pylori infection. Eur J Gastroenterol Hepatol 12: $497-503$

Zheng W, Sellers TA, Doyle TJ, Kushi LH, Potter JD, Folsom AR (1995) Retinol, antioxidant vitamins, and cancers of the upper digestive tract in a prospective cohort study of postmenopausal women. Am J Epidemiol 142: $955-960$ 